\title{
Hormonal and adaptive control of amino acid transport in muscle
}

By G. G. Guidotri, Istituto di Patologia Generale, Universita di Cagliari, Centro per lo Studio della Patologia Cellulare del C.N.R., Istituto di Patologia Generale, Università di Milano, Italy

The flow of chemical substances across membranes in the living cell has been studied extensively in recent years. In muscle tissue, amino acids are transported into the cells by saturable processes of mediation (Manchester, 1970; Guidotti, I 97I). Although many of the kinetic aspects of these processes and properties of the transport systems involved have now been elucidated (Akedo \& Christensen, 1962; Manchester, Guidotti, Borghetti \& Lüneburg, 1971), the accompanying regulatory aspects are still little known.

Among the various control mechanisms operating in a highly integrated organism, hormonal regulation of transmembrane transport is of major physiological importance (Riggs, 1970). On the other hand, adaptive mechanisms are essential factors for the modulation of transport processes in bacteria (Dietz \& Heppel, 197I ; Rosen, 197I) and low eucaryotes (Pall, I97I; Schneider \& Wiley, 1971). In this paper I wish to summarize a series of investigations (Guidotti, I97I; Guidotti, Borghetti, Lüneburg \& Gazzola, 1971; Gazzola, Franchi, Saibene, Ronchi \& Guidotti, 1972) and describe recent experiments carried out in my laboratory dealing with the hormonal and adaptive control of the transport of amino acids across the cell membrane in muscle tissue. Insulin, which is known to enhance the uptake of amino acids by muscle (Manchester, 1970; Guidotti, 197r), has been selected as hormonal effector. Chick embryo heart cells, as an insulin-sensitive muscle tissue that exhibits adaptive regulation of the activity of amino acid transport (Gazzola et al. 1972), have been used as the biological model.

The procedures of heart dissection from chick embryos and of cell isolation from hearts, together with the basic experimental methods, have been described in detail elsewhere (Guidotti, Kanameishi \& Foà, 196r; Guidotti, Borghetti, Gaja, Loreti, Ragnotti \& Foà, I968; Guidotti, Lüneburg \& Borghetti, I969).

\section{Hormonal regulation}

Isolated cardiac cells actively accumulate several analogues and naturally occurring amino acids in the intracellular compartment against a concentration difference. Insulin stimulates this process. Among analogues, the hormone has been shown to accelerate the uptake of $\alpha$-aminoisobutyric acid and cycloleucine (Manchester et al. 1971); enhanced accumulation of the naturally occurring glycine, alanine, serine, proline and methionine, and to a lesser extent, threonine and histidine, has 
been reported (Guidotti et al. 1969 and see Fig. 2). The inspection of these findings indicates that, with the exceptions of histidine and perhaps of threonine (on which the effect of insulin is very minor), all the amino acids that respond to insulin belong to the group taken up, primarily or appreciably, by the alanine-preferring or A system of mediation (Oxender \& Christensen, 1963 ), operative in chick embryo heart cells (Gazzola et al. 1972).

Studies with representative amino acids, under experimental conditions in which results approximated initial rates of entry or steady-state values of intracellular to extracellular distribution, indicated that insulin promoted the transport of these molecules into the heart tissue by increasing the effectiveness of saturable systems capable of producing uphill transport (Guidotti et al. 1968; Guidotti, 1971). The kinetic action of the hormone on these systems is consistent with an acceleration of the maximal velocity of transport without substantial changes in substrate concentration for half-maximal transport velocity (Guidotti et al. 1971). These results suggest a stepping up of the activity of the transport agencies involved either by enhancement of their capacity or by acceleration of the operational rate of the existing systems of mediation (at constant capacity).

Further investigations on the initial velocity of aminoisobutyrate uptake by isolated cardiac cells have been carried out in the presence and in the absence of inhibitors of protein and RNA synthesis (puromycin, cycloheximide and actinomycin D). The results provide evidence that insulin accelerates the transport of the analogue into the cells by a mechanism that does not require active protein and RNA synthesis (Fig. I). Therefore, activation of formerly inactive transport molecules or acceleration of the rate of operation of the existing machinery are favoured interpretations for the hormonal effect on amino acid transport.

\section{Adaptive regulation}

Experiments have been designed to investigate activity and kinetics of transport for analogue and natural amino acids as a function of time upon incubation of isolated cardiac cells under various in vitro conditions (active and inhibited protein and RNA synthesis; amino acid dependence; and transinhibition).

The results (Gazzola et al. 1972) indicate that the transport activity of a group of neutral amino acids, corresponding to those ascribed to the $A$ mediation by Christensen and co-workers (Oxender \& Christensen, I963; Christensen, I969), increases with time when the cells are incubated in Krebs-Ringer bicarbonate in the absence of added amino acids. This increase is abolished in the presence of puromycin, cycloheximide or actinomycin $\mathrm{D}$.

The increase in activity with time of the A transport system (investigated with $\alpha$ aminoisobutyric acid and proline as representative amino acids) is also prevented by the addition to the incubation medium of amino acids assigned to the same system of mediation on the basis of competition studies. It is not substantially altered by the addition of amino acids pertaining to the $L$ system of mediation or basic amino acids. Kinetic analyses of aminoisobutyrate uptake in which the transport of the analogue by the $A$ and $L$ systems of mediation could be separated 
Vol. 3I
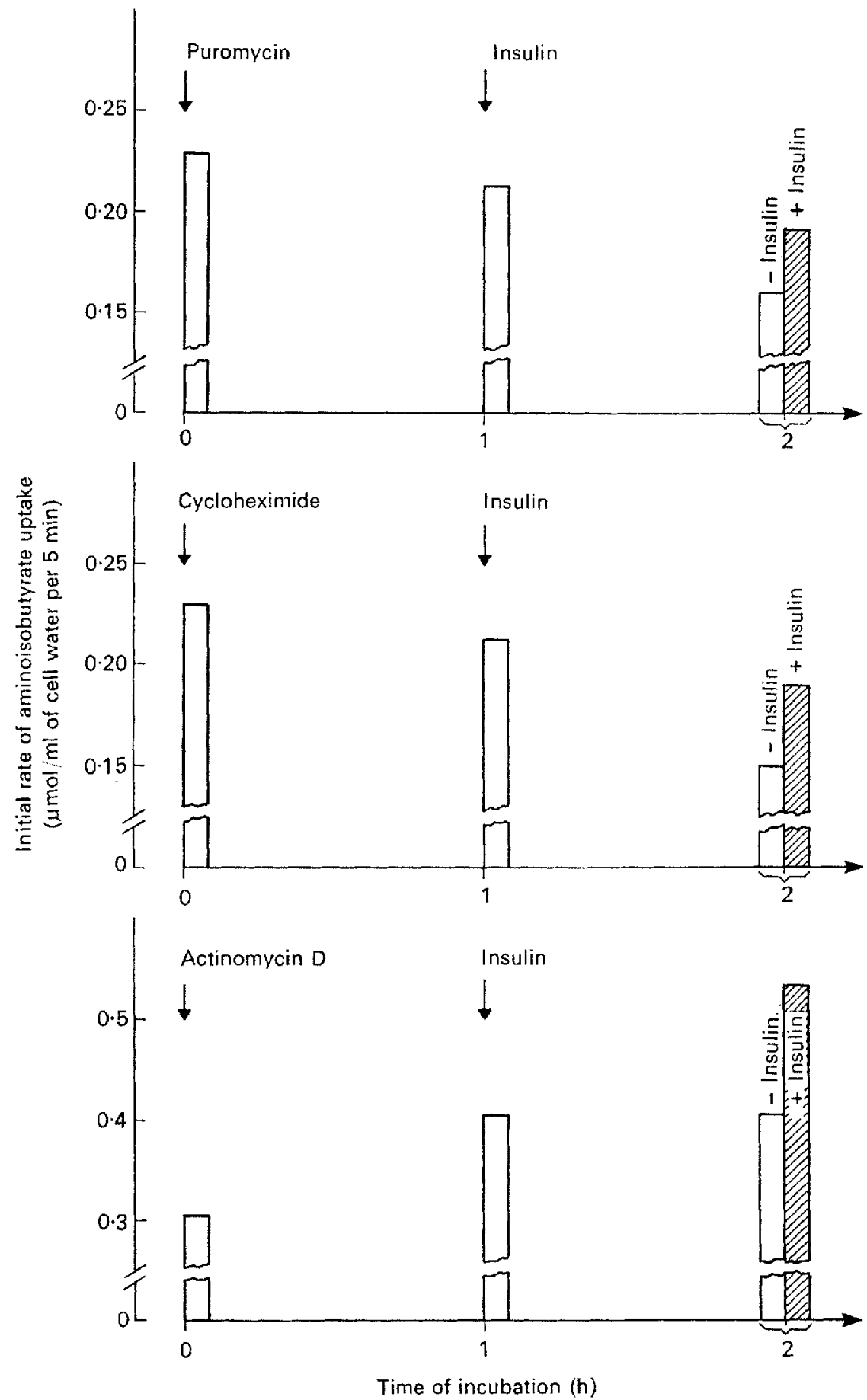

Fig. I. Effect of insulin on a-aminoisobutyric acid uptake by isolated cardiac cells under conditions of inhibited protein and RNA synthesis. Cell suspensions were incubated in Krebs-Ringer bicarbonate buffer, $\mathrm{pH} 7 \cdot 4$, containing $8 \mathrm{mmol}$ glucose and the inhibitor under study (puromycin $5 \circ \mu \mathrm{g} / \mathrm{ml}$; cycloheximide $5 \mu \mathrm{g} / \mathrm{ml}$; actinomycin $\left.\mathrm{D}_{\mathrm{I}} \mu \mathrm{g} / \mathrm{ml}\right)$. Incubation was at $37.5^{\circ}$ in an atmosphere of $\mathrm{O}_{2}+\mathrm{CO}_{2}(95: 5)$. After $I h$ insulin $(0.2$ unit $/ \mathrm{ml})$ was added and the incubation continued for $I$ additional $h$. Amino acid uptake (initial velocity) was measured by transferring samples of cell suspension into flasks containing the same medium supplemented with ${ }^{14} \mathrm{C}$-labelled aminoisobutyrate (0.1 $\mathrm{mmol}$, final concentration) and incubating for $5 \mathrm{~min}$ at $375^{\circ}$. 
indicate that the regulation of the activity of amino acid transport by the A system occurs through a mechanism affecting the maximal velocity of the process, without substantial changes in substrate concentration for half-maximal transport velocity.

In order to search for possible transinhibition in the described experimental model, the activity of the A transport system has been measured upon incubation of isolated cardiac cells with cycloheximide in the presence and absence of amino acids. The results of these experiments (Gazzola et al. r $97^{2}$ ) suggest that, although the occurrence of transinhibition cannot be excluded, it is unlikely that this mechanism is of major importance in the regulation of the activity of the A transport system. Instead, a regulation on the basis of the availability of active transport molecules is favoured.

Changes in the availability of effector molecules of a transport agency might result from a repression-derepression mechanism subject to control by substrate molecules for which it is competent. To test this possibility, experiments have been designed in which a temporal separation of transcription and translation during time- and amino acid-dependent changes of transport activity has been achieved by specific inhibitors of protein and RNA synthesis. Cells previously incubated in amino acid-free medium containing cycloheximide (phase of inhibited translation) subsequently exhibit a net increase of transport activity when transferred into a medium containing repressive concentrations of amino acids or actinomycin $\mathrm{D}$ (phase of inhibited transcription). The presence of amino acids pertaining to the A system during prior incubation in cycloheximide prevents the increase of activity of the A transport system during subsequent incubation in cycloheximide-free actinomycin D-containing medium. These results suggest that mRNA, specific for the synthesis of protein(s) needed for the transport process by the A mediation, apparently accumulates in the cells under conditions of inhibited translation and renders feasible the concept that a regulation of transport activity might be operative at the transcription level in a muscle tissue.

Several investigators have emphasized the role of amino acid transport across membranes in regulating protein synthesis (Finerman, Downing \& Rosenberg, 1967; Phang, Finerman, Singh, Rosenberg \& Berman, 1971). Here I have shown that such regulation occurs for the synthesis of specific proteins required for the transport process itself.

\section{Conclusion}

'The results presented in the preceding paragraphs lead to the following consideration: in the chick embryo heart cell the group of amino acids which undergoes adaptive regulation of transport activity (A system) is essentially the same as that which responds to insulin with a marked increase of uptake: results presented in Fig. 2 substantiate this point. Moreover, both adaptive and hormonal regulations occur through a mechanism affecting the maximal velocity of transport.

The question then arises as to whether both control mechanisms act at the same site. Inferences from studies with specific inhibitors of protein and RNA synthesis suggest that adaptive regulation operates at the transcription level. Reports of 


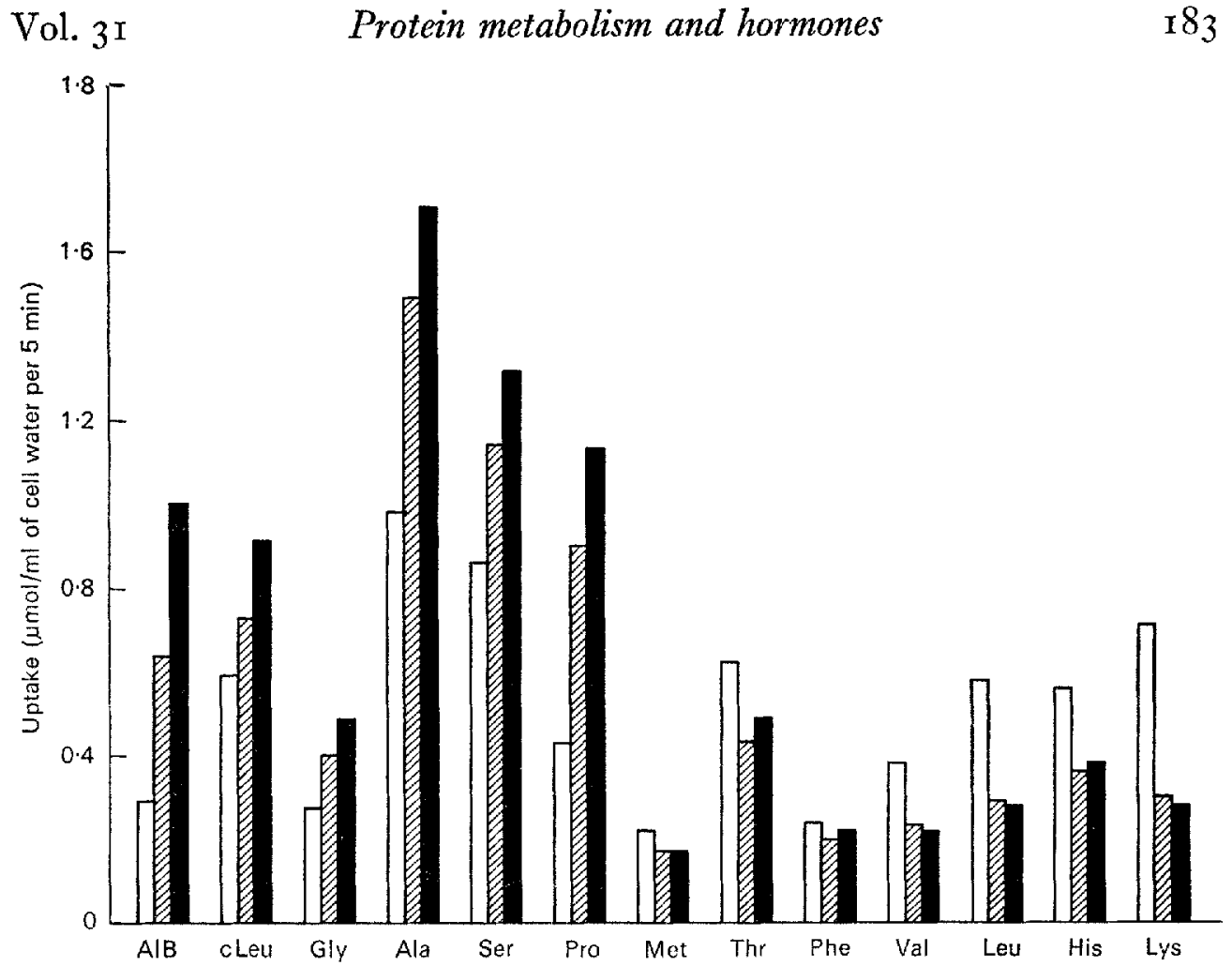

Fig. 2. Amino acid uptake by isolated cardiac cells: changes in transport activity with time and effcct of insulin thereon. Cell suspensions were incubated in Krebs-Ringer bicarbonate buffer, $\mathrm{pH} 7{ }^{4}$, containing $8 \mathrm{mmol}$ glucose, at $375^{\circ}$ in an atmosphere of $\mathrm{O}_{2}+\mathrm{CO}_{2}(95: 5)$. Amino acid uptake (initial velocity) was measured by transferring samples of cell suspension into flasks containing the same medium supplemented with the ${ }^{14} \mathrm{C}$-labelled amino acid ( $0 . \mathrm{I} \mathrm{mmol}$, final concentration) and incubating for $5 \mathrm{~min}$ at $375^{\circ}$. The plain columns are uptakes at the beginning of the incubation. Uptakes at the end of a $2 \mathrm{~h}$ incubation period in the absence and in the presence of insulin $(0.2$ unit $/ \mathrm{ml})$ are shown by shaded columns and black columns respectively. AIB, aminoisobutyric acid.

amino acid-dependent control of RNA synthesis in HeLa cells (Smulson \& Thomas, I969) and of selective sensitivity of an A-type transport system in rat intestine upon treatment with actinomycin D (Yamada, Clark \& Swendseid, I967) reinforce this concept. The fact that insulin stimulation of amino acid uptake by isolated cardiac cells remains effective for a few hours in the presence of inhibitors of protein and RNA synthesis suggests a different site for the action of the hormone. Unpublished experiments showing the persistence of an insulin effect in the presence of concentrations of amino acids capable of repressing the adaptive increase of transport activity of the $\mathrm{A}$ mediation are in accord with this view. A conclusive interpretation, however, must await the elucidation of the exact mechanism of insulin action.

Preliminary experiments provide evidence for the existence of adaptive regulation of amino acid transport activity also in such mammalian preparations as isolated rat diaphragm and mouse embryo heart, whose insulin-sensitivity, as far as amino acid uptake is concerned, is well documented. In the light of these findings, the molecular mechanism of the amino acid transport process appears much more 
complex than a mere sequence of binding-translocation-dissociation between substrate and effector structure across the cell membrane. Why the described regulatory influences are effective on the sole $\mathrm{A}$ mediation and how other transport systems for amino acids are regulated in muscle is still not known. Unfortunately, the lack of information as to the chemical nature of the constituents of the various transport agencies hinders progress in this field.

I am indebted to Drs G. C. Gazzola, R. Franchi, P. Ronchi and V. Saibene who allowed me to quote the results of their unpublished experiments.

This investigation was supported by Grant AM-05290 from the National Institute of Health, US Public Health Service, Bethesda, Md, USA.

\section{REFERENCES}

Akedo, H. \& Christensen, H. N. (1962). F. biol. Chem. 237, i 18.

Christensen, H. N. (1969). Adv. Enzymol. 32, x.

Dietz, G. W. \& Heppel, L. A. ( (97 I). F. biol. Chem. 246, 2885.

Finerman, G. A. M., Downing, S. \& Rosenberg, L. E. (1967). Biochim. biophys. Acta 135, 1008.

Gazzola, G. C., Franchi, R., Saibene, V., Ronchi, P. \& Guidotti, G. G. (r972). Biochim. biophys. Acta 266,407 .

Guidotti, G., Kanameishi, D. \& Foả, P. P. (1961). Am. F. Physiol. 201, 863.

Guidotti, G. G. (1971). In The Action of Hormones, Genes to Population p. I8I [P. P. Foà, editor]. Springfield, Ill.: C. C. Thomas.

Guidotti, G. G., Borghetti, A. F., Gaja, G., Loreti, L., Ragnotti, G. \& Foà, P. P. (1968), Biochem. $\mathcal{~}$. I07, 565 .

Guidotti, G. G., Borghetti, A. F., Lüneburg, B. \& Gazzola, G. C. (197I). Biochem. f. 122, 409.

Guidotti, G. G., Lüneburg, B. \& Borghetti, A. F. (I969). Biochem. F. 114, 97.

Manchester, K. L. (1970). In Biochemical Actions of Hormones p. 267 [G. Litwack, editor]. New York, NY: Academic Press.

Manchester, K. L., Guidotti, G. G., Borghetti, A. F. \& Lüneburg, B. (r97ı). Biochim. biophys. Acta 24I, 226.

Oxender, D. L. \& Christensen, H. N. (1963). F. biol. Chem. 238, 3686.

Pall, M. L. (1971). Biochim. biophys. Acta 233, 201.

Phang, J. M., Finerman, G. A. M., Singh, B., Rosenberg, L. E. \& Berman, M. (1971). Biochim. biophys. Acta $23^{\circ}, \mathbf{1}_{4} 6$.

Riggs, T. R. (I970). In Biochemical Actions of Hormones p. 157 [G. Litwack, editor]. New York, NY: Academic Press.

Rosen, B. P. (1971). Y. biol. Chem. 246, 3653 .

Schneider, R. P. \& Wiley, W. R. (1971). F. biol. Chem. 246, 4784 .

Smulson, M. E. \& Thomas, J. (1969). 7. biol. Chem. 244, 53 \%9.

Yamada, C., Clark, A. J. \& Swendseid, M. E. (1967). Science, N.Y. 158, 129. 